\title{
The Kesennuma Study in Miyagi, Japan: Study Design and Baseline Profiles of Participants
}

\author{
Mari Yamashita $^{1}$, Satoshi Seino ${ }^{1}$, Yu Nofuji ${ }^{1}$, Yasuhiro Sugawara ${ }^{1}$, \\ Yosuke Osuka $^{2}$, Akihiko Kitamura ${ }^{1}$, and Shoji Shinkai ${ }^{1,3}$ \\ ${ }^{1}$ Research Team for Social Participation and Community Health, Tokyo Metropolitan Institute of Gerontology, Tokyo, Japan \\ ${ }^{2}$ Research Team for Promoting Independence and Mental Health, Tokyo Metropolitan Institute of Gerontology, Tokyo, Japan \\ ${ }^{3}$ Undergraduate School of Nutrition Sciences, Kagawa Nutrition University, Saitama, Japan
}

Received December 16, 2020; accepted March 30, 2021; released online April 10, 2021

\begin{abstract}
Background: To clarify the association between psychosocial problems and frailty in the areas affected by the Great East Japan Earthquake, and to develop strategies for preventive long-term care in the community, we launched the Kesennuma Study in 2019. This report describes the study design and the participants' profiles at baseline.

Methods: The prospective study comprised 9,754 people (4,548 men and 5,206 women) randomly selected from communitydwelling independent adults aged 65 to 84 who were living in Kesennuma City, Miyagi. The baseline survey was conducted in October 2019. It included information on general health, socio-economic status, frailty, lifestyle, psychological factors (eg, personality, depressive moods), and social factors (eg, social isolation, social capital). A follow-up questionnaire survey is planned. Mortality, incident disability, and long-term care insurance certifications will also be collected.

Results: A total of 8,150 questionnaires were returned (83.6\% response rate), and 7,845 were included in the analysis ( $80.4 \%$; mean age 73.6 [standard deviation, 5.5] years; $44.7 \%$ male). About $23.5 \%$ were considered frail. Regarding psychological and social functions, $42.7 \%$ had depressive moods, $29.1 \%$ were socially isolated, and only $37.0 \%$ participated in social activities at least once a month. However, $82.5 \%$ trusted their neighbors.

Conclusions: While local ties were strong, low social activity and poor mental health were revealed as issues in the affected area. Focusing on the association between psychological and social factors and frailty, we aim to delay the need for long-term care for as long as possible, through exercise, nutrition, social participation, and improvement of mental health.
\end{abstract}

Key words: frailty; community-dwelling older adults; population approach; Kesennuma Study; psychological and social functions

Copyright $\odot 2021$ Mari Yamashita et al. This is an open access article distributed under the terms of Creative Commons Attribution License, which permits unrestricted use, distribution, and reproduction in any medium, provided the original author and source are credited.

\section{INTRODUCTION}

The Great East Japan Earthquake (GEJE) and tsunami in 2011 led to 15,899 deaths, and 2,528 missing and 6,157 injured people in Japan. ${ }^{1}$ More than 110,000 people had no choice but to live in prefabricated temporary housing for a long period; some continue to live in these conditions. Miyagi Prefecture reported 9,543 deaths and 1,216 missing and 4,145 injured people, making it one of the most severely affected areas. The infrastructure is recovering and no one was living in prefabricated temporary housing as of March 2020. ${ }^{2}$

A previous study assessing the long-term impact of GEJE on older residents reported that disability prevalence increased and sleep problems were more durably linked to material aspects of disaster damage. ${ }^{3-6}$ Moreover, some older people cannot adapt well to the new community and remain isolated. ${ }^{7}$ Thus, dealing with the psychosocial problems caused by GEJE is an urgent priority, to delay older adults entering long-term care and improve their health.
Frailty involves reduced ability to cope with age-associated stressors; it increases the risks of disability, institutionalization, and mortality. ${ }^{8}$ Frailty has been identified as a pre-stage of independence loss. Preventing frailty helps extend older adults' healthy life expectancy. ${ }^{9}$ The major independent risk factors for frailty have been classified as lower physical function, lower nutritional status, lower social function and social participation, and preclinical cardiovascular disease. ${ }^{10}$ Psychological factors, such as cognitive decline, depression, and loneliness, have been reported to be associated with frailty. ${ }^{11,12}$ However, in Japan, the association between psychological and social factors and frailty has not been established. It is necessary to find effective frailty prevention approaches, including psychological aspects, in areas affected by the GEJE.

To identify the associations between psychological and social factors and frailty in older adults according to sex and age, and find effective approaches to delay the need for long-term care in affected areas, we launched the Kesennuma Study in 2019. Here, we describe the study design and participants' profile at baseline. 


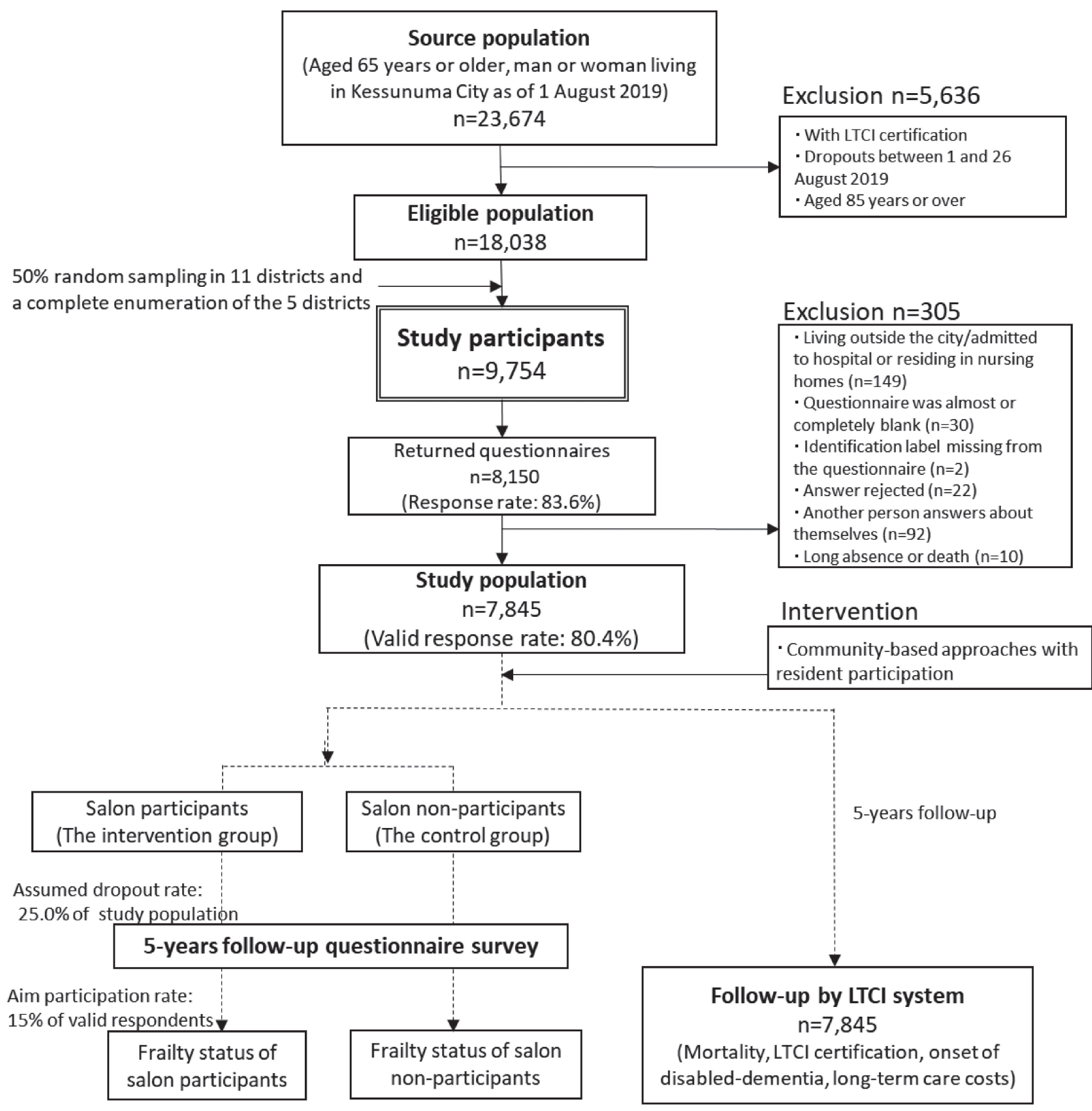

Figure 1. Flow diagram of study participants: the Kesennuma study in 2019

\section{METHODS}

\section{Study design, study setting, and participants}

The Kesennuma Study is a participatory action research (PAR) study ${ }^{13,14}$ based on a prospective cohort study design. The outcomes of the PAR are evaluated using a quasi-experimental design. ${ }^{15,16}$ Specifically, we aim to assess how psychological and social factors affect frailty through a cohort analysis. Moreover, we consider salons (a general term used in Japan to refer to places older adults can visit to carry out various activities) to be one of the hubs of community-based intervention and will compare frailty status between those who participate in the salon (the intervention group) and those who do not (the control group).

The source population comprised community-dwelling individuals aged 65 or older who lived in Kesennuma City in Miyagi
Prefecture, in north-east Japan, one of the GEJE disaster areas. Figure 1 depicts a flow diagram of the study participants. On August 1, 2019, the population aged 65 years or over comprised 23,674 people (10,286 men and 13,388 women). Additionally, the proportion of the population aged 65 and over was $37.1 \%$. Because frailty is a syndrome occurring before falling into a state of needing care, we excluded individuals who were certified for long-term care insurance (LTCI), hospitalized, or living in nursing homes. As we considered it would be a struggle for them to answer many items and return questionnaires by mail, individuals older than 85 years were excluded. The eligible population was 18,038 as of August 26, 2019. For each of Kesennuma Council of Social Welfare's 16 districts, the survey was conducted using 50\% random sampling in 11 large districts and a complete enumeration of the 5 smaller districts (target 
populations $\leq 501)$. Finally, 9,754 people (4,548 men and 5,206 women) were included. To combine the baseline and follow-up survey data, we added identification numbers to questionnaires. The basis for the sample size was calculated as follows. First, Nofuji et $\mathrm{al}^{17}$ reported that the prevalence of frailty in participants and non-participants in the frailty prevention class was $17.1 \%$ and $24.1 \%$, respectively. To detect this difference of about $7 \%$ using a chi-square test, 521 subjects in each of the intervention (salon participants) and non-intervention groups (salon non-participants) were required (statistical power 0.8, risk level 0.05). Second, based on a survey by Nofuji et al, ${ }^{17}$ it was expected that about $25.0 \%$ participants at the baseline will drop out 5 years later. Third, considering the baseline survey results, the valid response rate was expected to be $80 \%$. In addition, the target rate for participation to salons, which Kesennuma City is aiming for, was approximately $15.0 \%$. From the above, the number of subjects required for the baseline survey was calculated to be 7,236.

On October 4, 2019, we mailed self-administered questionnaires and requested them to be returned by October 18, 2019. Non-responders were sent postcard reminders and asked to return their questionnaires by November 1, 2019. To increase effective answers, we conducted telephone interview surveys on 830 incomplete questionnaires from November 15 to December 23, 2019.

\section{Baseline survey}

Table 1 summarizes the main measures surveyed at baseline. ${ }^{10,18-20,23-37}$ The key measures include frailty status (primary outcome) and psychological and social variables (secondary outcomes). Other factors, such as physical function and nutrition status, which have been reported to be related to frailty, ${ }^{10}$ and the effects of the GEJE and socio-economic status were selected as confounding factors (additional measures).

\section{Primary outcome measures}

Frailty status was assessed using a Check-List 15 (CL15) score of $\geq 4 .^{10,18-20}$ The CL15 had three dimensions and 15 items consisting of five items of homeboundness, six items of falling, and four items of lower nutrition (eTable 1). The index score ranges from 0 to 15 , with a higher score indicating a greater likelihood of frailty. Shinkai et a ${ }^{19}$ reported that a cut-off score of $3 / 4$ discriminated Fried's definition frailty ${ }^{21}$ from non-frailty with a sensitivity of $70.0 \%$ and specificity of $89.3 \%$. The CL15 is strongly correlated with the Frailty Index, ${ }^{22}$ a significant predictor of LTCI certification and/or mortality, and is compatible with the Frailty Index in predicting risk. ${ }^{20}$

\section{Secondary outcome measures}

Psychological information included current feeling, ${ }^{23-26}$ subjective well-being, ${ }^{27}$ subjective cognitive decline, ${ }^{28}$ and personality. ${ }^{29}$ Current feeling included depressive moods, ${ }^{23,24}$ apathy, ${ }^{25}$ and loneliness. ${ }^{26}$ The above indicators have been validated, and other questions were asked about trauma ("When remembering past sorrows and unpleasant experiences, do you often feel gloomy?') and anxiety ('Do you often feel vague uneasiness about the future?').

Assessed social functions included social network, ${ }^{30}$ frequency of outings, ${ }^{31}$ and cognitive social capital ('Do you trust your neighbors?'). Social network included social isolation, ${ }^{30}$ social participation (volunteer, sports, and hobby groups, and senior citizen clubs, neighborhood associations, and salon activities),
Table 1. Outline of baseline self-administered questionnaire on the Kesennuma Study 2019

\begin{tabular}{|c|c|}
\hline \multicolumn{2}{|l|}{ Primary outcome measures } \\
\hline Frailty & CL15 ${ }^{10,18-20}$ \\
\hline \multicolumn{2}{|l|}{ Secondary outcome measures } \\
\hline \multirow[t]{4}{*}{ Psychological function } & Current feeling ${ }^{23-26}$ \\
\hline & Subjective well-being ${ }^{27}$ \\
\hline & Subjective cognitive decline $e^{28}$ \\
\hline & Personality traits (TIPI-J) ${ }^{29}$ \\
\hline \multirow[t]{3}{*}{ Social function } & Social network ${ }^{30}$ \\
\hline & Frequency of outings ${ }^{31}$ \\
\hline & Cognitive social capital (trust in neighbours) \\
\hline \multicolumn{2}{|l|}{ Additional measures } \\
\hline \multirow[t]{3}{*}{ Demographics } & Age, sex \\
\hline & Years of residence in the neighbourhood \\
\hline & Living arrangement \\
\hline \multirow[t]{3}{*}{ Socio-economic status } & Education \\
\hline & Taxation status \\
\hline & Current job \\
\hline \multirow{8}{*}{ Medical and lifestyle profiles } & Drinking habits, smoking status \\
\hline & $\begin{array}{l}\text { Self-rated health, history of physician-diagnosed } \\
\text { diseases }\end{array}$ \\
\hline & Body mass index \\
\hline & Musculoskeletal pain, mobility limitation ${ }^{32,33}$ \\
\hline & Regular exercise, sitting time ${ }^{34}$ \\
\hline & Dietary information: DVS, ${ }^{35,36}$ eating alone \\
\hline & Sleep-related items \\
\hline & Higher-level competence, TMIG-IC ${ }^{37}$ \\
\hline \multirow[t]{3}{*}{ GEJE-related items } & Number of relocations \\
\hline & Current home \\
\hline & Change in consultation access \\
\hline
\end{tabular}

CL15, Check-List $15^{10,18-20}$; DVS, Dietary Variety Score ${ }^{35,36}$; TIPI-J, Ten Item Personality Inventory ${ }^{29}$; TMIG-IC, Tokyo Metropolitan Institute of Gerontology Index of Competence. ${ }^{37}$

History of physician-diagnosed diseases: hypertension, dyslipidemia, heart disease, stroke, diabetes, bone disease, respiratory organs, cancer.

Sleep-related items: sleep duration, difficulty falling asleep, quality of sleep.

social support, and conversation with others ('Do you talk to someone every day?'). Social support included availability of instrumental support ('Can anyone help you when you are in trouble?'), informational support ('Can anyone give you information and knowledge that you need?'), and emotional support ('Is there anyone with whom you can share your worries and feelings?'). Face-to-face and non-face-to-face contact with people outside of the household less than 1 day a week is used as an operational definition of social isolation. ${ }^{30}$ The standard of outing frequency that has been shown to be associated with functional decline in the elderly is less than 1 day a week. ${ }^{31}$ Other question items about social network and cognitive social capital have not been validated and are customarily used.

\section{Additional measures}

As additional measures, demographics, socio-economic status, medical and lifestyle profiles, and GEJE-related items were collected. GEJE-related items included number of relocations, current home, and change in consultation access. Answers to change-related question were organized in three groups: positive change ('Did you have more people to talk to?'), negative change ('Did you have fewer people to talk to?'/'I don't know what to do when I face difficulties'), and unchanged. GEJErelated items were questions decided in consultation with Kesennuma City. 


\section{Intervention overview}

Kesennuma City signed a comprehensive cooperation agreement with us in November 2018 to improve regional issues. As such, this study is planned as a joint project to delay the need for longterm care among older residents. First, to understand regional issues and discuss frailty prevention, resident-organized community meetings were held in all 16 districts between July and October 2019. At these community meetings, each district was presented with its results from the baseline survey. Inspired by these findings, residents have begun taking actions to improve issues in their areas. Second, we are planning actions to enhance frailty prevention knowledge levels and behaviors. We educate resident leaders and volunteers in frailty prevention knowledge and implement exercise, nutrition, and social function improvement programmes ${ }^{17}$ for other residents. Furthermore, we plan to use and expand the salon as a place to provide such activities. Finally, we added frailty prevention elements to activities already underway. These steps are based on the PAR framework. ${ }^{13,14}$

\section{Follow-up surveys}

We plan to conduct a follow-up questionnaire survey 5 years after the baseline survey, which will be mailed to the baseline survey respondents. The follow-up survey will include items related to frailty (primary outcome) and psychological and social factors (secondary outcomes).

In Japan, all individuals aged 65 years or older are eligible for LTCI benefits, and the LTCI system monitors an individual's LTCI usage via their municipal government. The LTCI classifies individuals as 'Support Level 1 or 2' to indicate the need for assistance with basic activities of daily living or 'Care Level 1 through 5' to indicate the need for continuous care. ${ }^{38}$ The degree of independence in daily life specified for individuals with dementia is listed separately. The date and time of death or transfer from Kesennuma City are also recorded. In this study, the participants will be tracked monthly regarding the LTCI benefits received for 5 years after the baseline survey, to confirm four outcomes: mortality, LTCI certification, onset of disableddementia, and long-term care costs. The LTCI information will be provided to us by Kesennuma City.

\section{Ethical considerations}

The study protocol was approved by the Ethical Committee of the Tokyo Metropolitan Institute of Gerontology (August 25, 2019). All participants gave informed consent. A statement attached to the questionnaire explained the study's purpose, the voluntary nature of participation, and confirmed the analysis was anonymous. Returning the questionnaire was viewed as consent to participate.

\section{Statistical analyses}

To describe the study participants' characteristics at baseline, taking into account sex and age, we compared the main measures between participants grouped by age (65-74 and 75-84 years old) and sex (male and female) using the chi-square test for nominal variables, the Kruskal-Wallis test for ordinal variables, and oneway analysis of variance for continuous variables. When comparing Kesennuma City's characteristics with those of other areas, we used the independent $t$-test for continuous variables and chi-square test for categorical variables. $P$-values under 0.05 on a two-tailed test were regarded as statistically significant. SPSS version 25.0 (IBM Corp., Armonk, NY, USA) was used for statistical analyses.
Table 2. The collection status of the 16 districts

\begin{tabular}{|c|c|c|c|c|}
\hline District & $\begin{array}{c}\text { Target population } \\
n\end{array}$ & $\begin{array}{c}\text { Study participants } \\
n(\%)\end{array}$ & $\begin{array}{c}\text { Returned } \\
\text { questionnaires } \\
n(\%)\end{array}$ & $\begin{array}{c}\text { Study population } \\
n(\%)\end{array}$ \\
\hline $\mathrm{A}$ & 2,101 & $1,050(50.0)$ & $874(83.2)$ & $842(80.2)$ \\
\hline $\mathrm{B}$ & 1,253 & $626(50.0)$ & $529(84.5)$ & 511 (81.6) \\
\hline $\mathrm{C}$ & 222 & $222(100.0)$ & $182(82.0)$ & $171(77.0)$ \\
\hline $\mathrm{D}$ & 263 & $263(100.0)$ & $218(82.9)$ & 212 (80.6) \\
\hline $\mathrm{E}$ & 134 & $134(100.0)$ & $114(85.1)$ & $111(82.8)$ \\
\hline $\mathrm{F}$ & 501 & $501(100.0)$ & $402(80.2)$ & $381(76.0)$ \\
\hline $\mathrm{G}$ & 1,418 & $709(50.0)$ & $577(81.4)$ & $552(77.9)$ \\
\hline $\mathrm{H}$ & 2,454 & $1,227(50.0)$ & $1,041(84.8)$ & $1,016(82.8)$ \\
\hline I & 1,546 & $773(50.0)$ & $667(86.3)$ & $648(83.8)$ \\
\hline $\mathrm{J}$ & 1,133 & $566(50.0)$ & $458(80.9)$ & $444(78.4)$ \\
\hline $\mathrm{K}$ & 1,621 & $810(50.0)$ & $701(86.5)$ & $678(83.7)$ \\
\hline $\mathrm{L}$ & 903 & $451(50.0)$ & $366(81.2)$ & $343(76.1)$ \\
\hline $\mathrm{M}$ & 1,860 & $930(50.0)$ & $790(84.9)$ & $749(80.5)$ \\
\hline $\mathrm{N}$ & 357 & 357 (100.0) & $290(81.2)$ & $279(78.2)$ \\
\hline $\mathrm{O}$ & 1,269 & $634(50.0)$ & $517(81.5)$ & $495(78.1)$ \\
\hline $\mathrm{P}$ & 1,003 & $501(50.0)$ & $422(84.2)$ & $413(82.4)$ \\
\hline Total & 18,038 & $9,754(54.1)$ & $8,148(83.5)$ & $7,845(80.4)$ \\
\hline
\end{tabular}

Note: Two returned questionnaires lost their identification labels and could not be classified by district.

\section{RESULTS}

Of the 9,754 people surveyed, we collected questionnaires from 8,150 (response rate of $83.6 \%$ ). A total of 305 people were excluded, including unidentified people, blank entries, peeled-off labels, those clearly answered by another person (non-matching sex and age), hospitalization, refusal to respond, long-term absence, or death. The analysis was conducted on data from 7,845 individuals (valid response rate of $80.4 \%$ ). Table 2 shows the collection status by the 16 districts.

Table 3 shows participants' baseline characteristics regarding the additional measures. The mean age was 73.6 (standard deviation, 5.5) years, $44.7 \%$ of participants were men, and $94.2 \%$ had lived in their community for 30 years or more. Being widowed, living alone, and being unemployed were more frequent in women aged 75 or older. A higher proportion of men had previous or current drinking and smoking habits. The proportion of people who felt healthy and had no chronic disease was higher among people aged 65 to 74 compared to those 75 or older, regardless of sex. Being underweight (body mass index $<18.5 \mathrm{~kg} / \mathrm{m}^{2}$ ), having musculoskeletal pain, having mobility limitation, and having sleep disorders were more frequent in women aged 75 or older. The proportion of obesity (body mass index $\geq 25.0 \mathrm{~kg} / \mathrm{m}^{2}$ ) was inversely associated with being a man aged 65 to 74 . Dietary variety scores and Tokyo Metropolitan Institute of Gerontology Index of Competence (TMIG-IC) scores were higher among women in both age groups. After GEJE, $30.7 \%$ had relocated at least once. Relocating three or more times after GEJE was more frequent in women aged 75 or older than other groups. Regarding changes in post-GEJE consultation access, $66.1 \%$ of people answered that there was no change, although people aged 75 or over felt more negative changes. 
Table 3. Participants' baseline characteristics: additional measures

\begin{tabular}{|c|c|c|c|c|c|c|c|}
\hline & \multirow[b]{2}{*}{$n(\%)$} & \multirow{2}{*}{$\begin{array}{l}\text { Total } \\
7,845\end{array}$} & \multicolumn{2}{|c|}{ Men } & \multicolumn{2}{|c|}{ Women } & \multirow[b]{2}{*}{$P$} \\
\hline & & & $\begin{array}{l}65-74 \text { years old } \\
2,022(25.8)\end{array}$ & $\begin{array}{l}75-84 \text { years old } \\
1,488(19.0)\end{array}$ & $\begin{array}{l}65-74 \text { years old } \\
2,378(30.3)\end{array}$ & $\begin{array}{l}75-84 \text { years old } \\
1,957(24.9)\end{array}$ & \\
\hline \multicolumn{8}{|l|}{ Demographics } \\
\hline \multirow{2}{*}{$\begin{array}{l}\text { Age, years } \\
\text { Years of residence in the neighbourhood, } \\
n(\%)\end{array}$} & Mean (SD) & $73.6(5.5)$ & $69.4(2.7)$ & $78.9(2.8)$ & $69.5(2.6)$ & $79.1(2.8)$ & - \\
\hline & $<10$ & $144(1.9)$ & $46(2.3)$ & $23(1.6)$ & $45(1.9)$ & $30(1.6)$ & \\
\hline & $10-29$ & $299(3.9)$ & $89(4.5)$ & $54(3.7)$ & $101(4.3)$ & $55(2.9)$ & * \\
\hline & $30-59$ & $2,406(31.4)$ & $478(24.2)$ & $392(27.2)$ & $924(39.4)$ & $612(32.3)$ & \\
\hline & $>59$ & $4,816(62.8)$ & $1,366(69.0)$ & $974(67.5)$ & $1,277(54.4)$ & $1,199(63.2)$ & \\
\hline Marital status, $n(\%)$ & Married & $5,363(71.3)$ & $1,615(82.3)$ & $1,186(84.4)$ & $1,650(71.0)$ & $912(49.8)$ & \\
\hline & Divorced & $331(4.4)$ & $100(5.1)$ & $38(2.7)$ & $153(6.6)$ & $40(2.2)$ & * \\
\hline & Widowed & $1,552(20.6)$ & $113(5.8)$ & $147(10.5)$ & $458(19.7)$ & $834(45.5)$ & \\
\hline & Never married & $278(3.7)$ & $135(6.9)$ & $35(2.5)$ & $63(2.7)$ & $45(2.5)$ & \\
\hline Living alone & Yes, $n(\%)$ & $1,020(13.3)$ & 235 (11.9) & $123(8.6)$ & $287(12.2)$ & $375(19.8)$ & * \\
\hline Socio-economic status & & & & & & & \\
\hline Years of education, $n(\%)$ & Other/Unknown & $154(2.0)$ & $30(1.5)$ & $18(1.2)$ & $58(2.5)$ & $48(2.5)$ & \\
\hline & $<12$ & $2,964(38.7)$ & $732(36.9)$ & $710(49.2)$ & $603(25.8)$ & $919(48.7)$ & * \\
\hline & $\geq 12$ & $4,532(59.2)$ & $1,223(61.6)$ & $714(49.6)$ & $1,673(71.7)$ & $922(48.8)$ & \\
\hline Taxation status, $n(\%)$ & Tax-free & $2,103(26.8)$ & $346(17.1)$ & $374(25.1)$ & $650(27.3)$ & $733(37.5)$ & \\
\hline & Tax-free, but cohabitant is taxed & $2,661(33.9)$ & $236(11.7)$ & $262(17.6)$ & $1,150(48.4)$ & $1,013(51.8)$ & * \\
\hline & Taxed, $<1.2$ million yen & $1,397(17.8)$ & $479(23.7)$ & $440(29.6)$ & $360(15.1)$ & $118(6.0)$ & \\
\hline & Taxed, $\geq 1.2$ million yen & $1,684(21.5)$ & $961(47.5)$ & $412(27.7)$ & $218(9.2)$ & $93(4.8)$ & \\
\hline Current job, $n(\%)$ & Full-time & $1,321(17.9)$ & $683(34.7)$ & $186(13.2)$ & $325(14.3)$ & $127(7.3)$ & \\
\hline & Part-time & $1,612(21.8)$ & $500(25.4)$ & $330(23.5)$ & $492(21.7)$ & $290(16.6)$ & * \\
\hline & Unemployed & $4,449(60.3)$ & $783(39.8)$ & $891(63.3)$ & $1,449(63.9)$ & $1,326(76.1)$ & \\
\hline Medical and lifestyle profiles & & & & & & & \\
\hline Drinking habits, $n(\%)$ & Current & $2,820(36.3)$ & $1,349(67.0)$ & $765(52.1)$ & $505(21.4)$ & $201(10.5)$ & \\
\hline & Former & $1,102(14.2)$ & $337(16.7)$ & $387(26.3)$ & $224(9.5)$ & $154(8.0)$ & * \\
\hline & Never & $3,837(49.5)$ & $327(16.2)$ & $317(21.6)$ & $1,627(69.1)$ & $1,566(81.5)$ & \\
\hline Smoking status, $n(\%)$ & Current & $837(10.8)$ & $510(25.3)$ & $198(13.5)$ & $93(3.9)$ & $36(1.9)$ & \\
\hline & Former & $2,267(29.2)$ & $1,111(55.2)$ & $867(59.0)$ & $198(8.4)$ & $91(4.7)$ & * \\
\hline & Never & $4,656(60.0)$ & $392(19.5)$ & 405 (27.6) & $2,067(87.7)$ & $1,792(93.4)$ & \\
\hline Self-rated health & Excellent to good, $n(\%)$ & $5,288(72.5)$ & $1,424(75.1)$ & 905 (66.6) & $1,752(77.9)$ & $1,207(67.2)$ & * \\
\hline Number of chronic diseases, $n(\%)$ & 0 & $929(12.1)$ & $271(13.6)$ & $144(9.9)$ & $344(14.7)$ & $170(8.9)$ & \\
\hline & 1 & $2,049(26.7)$ & $531(26.7)$ & $372(25.7)$ & $667(28.5)$ & $479(25.1)$ & * \\
\hline & $\geq 2$ & $4,704(61.2)$ & $1,188(59.7)$ & $934(64.4)$ & $1,326(56.7)$ & $1,256(65.9)$ & \\
\hline BMI $\left(\mathrm{kg} / \mathrm{m}^{2}\right), n(\%)$ & $<18.5$ & $402(5.2)$ & $49(2.4)$ & $62(4.3)$ & $141(6.0)$ & $150(8.0)$ & \\
\hline & $18.5-24.9$ & $5,087(66.3)$ & $1,333(66.5)$ & $960(66.8)$ & $1,573(67.0)$ & $1,221(64.8)$ & $*$ \\
\hline & $\geq 25.0$ & $2,185(28.5)$ & $623(31.1)$ & $416(28.9)$ & $634(27.0)$ & $512(27.2)$ & \\
\hline Musculoskeletal pain & Shoulder, yes, $n(\%)$ & $1,438(21.4)$ & $389(21.1)$ & $285(22.8)$ & 393 (18.6) & $371(24.6)$ & * \\
\hline & Lower back, yes, $n(\%)$ & $2,204(31.1)$ & $518(27.0)$ & $451(34.0)$ & $578(26.5)$ & $657(39.7)$ & * \\
\hline & Knee, yes, $n(\%)$ & $1,975(27.8)$ & $367(19.6)$ & $358(27.5)$ & $584(26.2)$ & $666(39.3)$ & * \\
\hline Mobility limitation & With, $n(\%)$ & $2,619(34.1)$ & $373(18.8)$ & $547(38.0)$ & $639(27.2)$ & $1,060(55.3)$ & * \\
\hline $\begin{array}{l}\text { Engaging in any exercise more than once } \\
\text { a week }\end{array}$ & Yes, $n(\%)$ & $5,034(65.9)$ & $1,215(60.8)$ & $1,017(70.6)$ & $1,490(63.9)$ & $1,312(70.1)$ & * \\
\hline Sitting time & Hours, mean (SD) & $5.8(3.9)$ & $5.4(3.9)$ & $5.7(3.9)$ & $5.8(3.8)$ & $6.3(4.0)$ & * \\
\hline DVS & Score, mean (SD) & $3.8(2.4)$ & $3.1(2.3)$ & $3.8(2.4)$ & $4.0(2.4)$ & $4.4(2.4)$ & $*$ \\
\hline & Score $\geq 4, n(\%)$ & $3,674(51.5)$ & $739(39.2)$ & $656(49.5)$ & $1,223(55.3)$ & $1,056(61.8)$ & $*$ \\
\hline Eating alone & Mainly eats alone, $n(\%)$ & $969(12.4)$ & $274(13.6)$ & $153(10.4)$ & $216(9.1)$ & $326(16.7)$ & $*$ \\
\hline & $\begin{array}{l}\text { Times eating alone per week, } \\
\text { mean (SD) }\end{array}$ & $1.6(2.6)$ & $1.6(2.6)$ & $1.3(2.4)$ & $1.4(2.5)$ & $2.0(2.9)$ & $*$ \\
\hline Difficulty falling asleep $(\geq 30)$ & With, $n(\%)$ & $3,318(44.5)$ & $705(35.9)$ & 647 (45.9) & $989(43.3)$ & $977(54.4)$ & * \\
\hline Quality of sleep & Excellent to good, $n(\%)$ & $5,677(73.4)$ & $1,476(73.5)$ & $1,125(76.9)$ & $1,706(72.5)$ & $1,370(71.5)$ & * \\
\hline TMIG-IC (0-13) & Score $\geq 11, n(\%)$ & $5,934(80.1)$ & $1,451(74.7)$ & $945(68.9)$ & $2,080(90.5)$ & $1,458(81.2)$ & * \\
\hline GEJE-related items & & & & & & & \\
\hline Number of relocations, $n(\%)$ & 0 & $5,333(69.3)$ & $1,411(70.7)$ & $1,017(70.0)$ & $1,627(69.1)$ & $1,278(67.5)$ & \\
\hline & 1 & $715(9.3)$ & $199(10.0)$ & $156(10.7)$ & $201(8.5)$ & $159(8.4)$ & * \\
\hline & 2 & $760(9.9)$ & $201(10.1)$ & $125(8.6)$ & $233(9.9)$ & $201(10.6)$ & \\
\hline & $\geq 3$ & $888(11.5)$ & $186(9.3)$ & $154(10.6)$ & $292(12.4)$ & $256(13.5)$ & \\
\hline Current home, $n(\%)$ & Same as before disaster & $5,344(69.1)$ & $1,420(71.0)$ & $1,027(70.2)$ & $1,635(69.5)$ & $1,262(65.9)$ & \\
\hline & Disaster public housing complex & $224(2.9)$ & $66(3.3)$ & $42(2.9)$ & $72(3.1)$ & $44(2.3)$ & \\
\hline & Group relocated housing complex & $1,061(13.7)$ & $255(12.8)$ & $189(12.9)$ & $328(13.9)$ & $289(15.1)$ & * \\
\hline & Rented house & $573(7.4)$ & $113(5.7)$ & $107(7.3)$ & $163(6.9)$ & $190(9.9)$ & \\
\hline & Independent reconstruction house & $303(3.9)$ & $84(4.2)$ & $51(3.5)$ & $89(3.8)$ & $79(4.1)$ & \\
\hline & Other & $226(2.9)$ & $62(3.1)$ & $46(3.1)$ & $66(2.8)$ & $52(2.7)$ & \\
\hline Change in consultation access, $n(\%)$ & Positive change & $757(10.1)$ & $134(6.9)$ & $121(8.6)$ & $248(10.8)$ & $254(13.9)$ & \\
\hline & Negative change & $1,774(23.7)$ & $422(21.6)$ & $392(27.8)$ & $441(19.3)$ & $519(28.4)$ & * \\
\hline & Unchanged & $4,942(66.1)$ & 1,395 (71.5) & 895 (63.6) & $1,600(69.9)$ & $1,052(57.6)$ & \\
\hline
\end{tabular}

BMI, body mass index; TMIG-IC, Tokyo Metropolitan Institute of Gerontology Index of Competence.

Note: Missing values were removed; $P$-value for the difference among four groups: ${ }^{*} P<0.001$. 
Study Design: Frailty in Kesennuma City in Japan

Table 4. Participants' baseline characteristics: frailty and psychological and social function

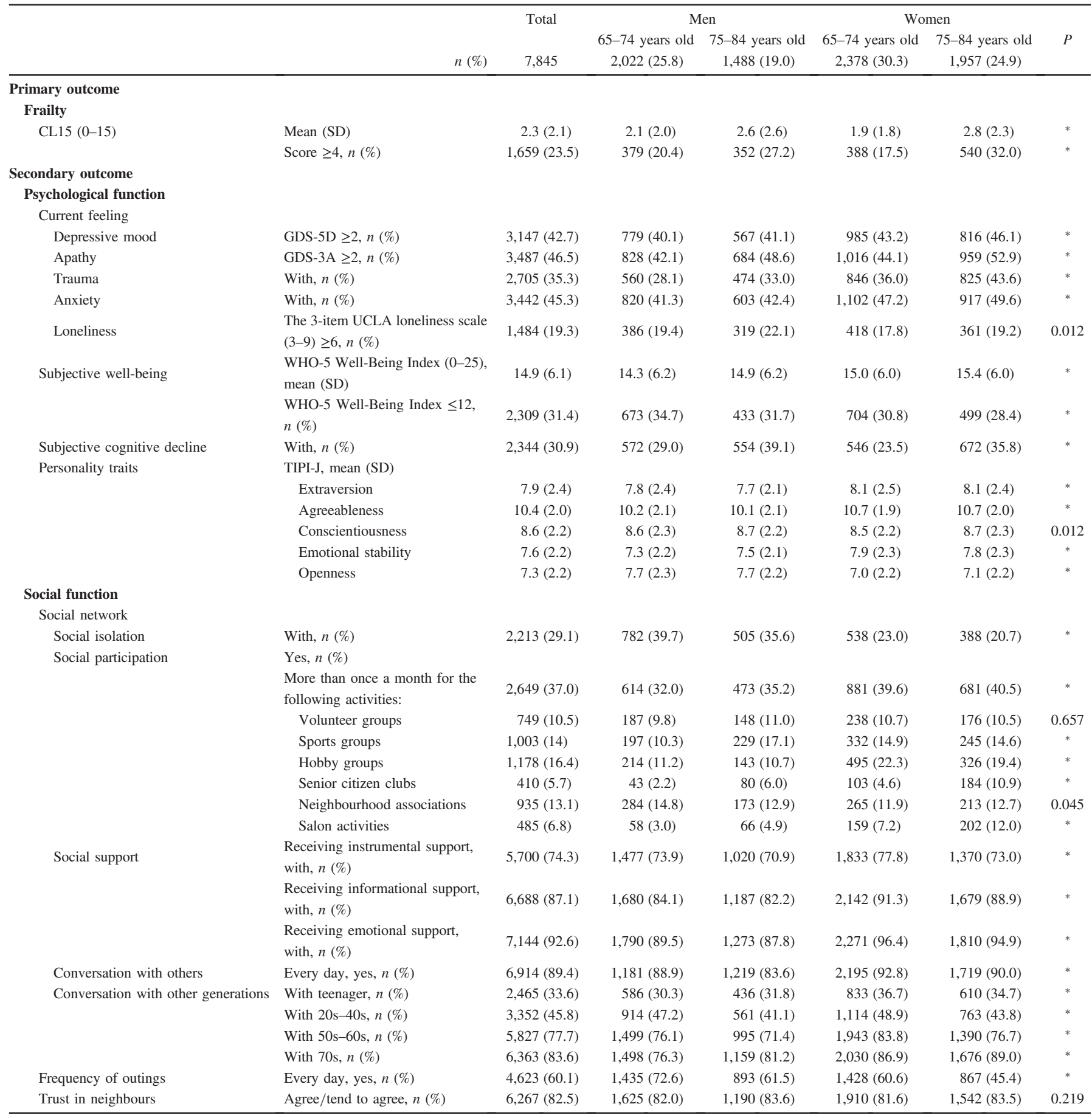

GDS, Geriatrics Depression Scale; CL15, Check-List 15; TIPI-J, Ten Item Personality Inventory.

Note: Missing values were removed; $P$-value for the difference among four groups: ${ }^{*} P<0.001$.

Table 4 shows frailty and psychological and social function baseline characteristics. Overall, $23.5 \%$ of participants were frail; the ratio was higher among people aged 75 or over regardless of sex. Regarding psychological function, depressive moods, apathy, and trauma were more frequent in women aged 75 or older. Women were more anxious than men. Loneliness was most prevalent among men aged 75 or older. Regarding social function, $29.1 \%$ of participants had no contact with others apart from their cohabitating family each week and $37.0 \%$ participated in social activities at least once a month. Men tended to be isolated and to have low levels of social activities. However, there was no sex difference in social capital.

\section{DISCUSSION}

It was difficult to compare these participants' baseline profiles with those of other GEJE-affected area studies because the measures used were different. Therefore, we compared our results 
with another cohort, Ota City in Tokyo (The Ota Genki Senior Project) ${ }^{39}$ In brief, Ota City is one of the urban areas in Tokyo, with a population of over 700,000. The Ota Genki Senior Project was a PAR for developing a prototype of a frailty prevention strategy for an urban area. In contrast, Kesennuma City is a coastal rural area with less than one-tenth of the population of Ota City, but both studies used similar indicators (eTable 2).

There was no significant difference in the prevalence of frailty. Kesennuma's exercise engagement, social participation, and outing frequency were lower, which may be related to high obesity and mobility restrictions. The proportion of people suffering from depressive moods was higher. Regarding social isolation, the results were not significantly different from the urban area, which was reported to have high social isolation. ${ }^{40,41}$ However, trust in neighbors was a lot higher, which will be a strength in promoting community intervention.

Following reporting of baseline survey results at community meetings in all 16 districts, subsequent actions have been discussed. To deal with isolation and psychological problems, approaches to individuals who had psychosocial rather than physical difficulties in accessing places for social participation were considered. Our intervention will be based on four pillars: exercise, nutrition, social participation, and improvement of mental health.

Our study's strengths are as follows. First, our response rate of 86.3\% means our survey was extensively conducted among community-dwelling older people. Therefore, selection or response bias possibility should be relatively low. By linking the baseline and follow-up data, we will be able to assess various associations and outcomes reflecting the actual conditions of the source population, including an evaluation of the effects of community-based population approaches to frailty prevention. Second, the baseline survey assessed various measures of psychological and social factors, enabling an exploration of the effects of psychological and social factors on frailty from several perspectives.

Our study has some limitations. First, the self-administered questionnaire may be subject to recall bias. Second, the reproducibility of CL15, which is the main outcome, has not been confirmed. Variables about trauma, anxiety, and some social functions were not adequately validated. Third, we did not obtain information before GEJE; its direct impact cannot, therefore, be considered. Finally, this study does not have a randomized design. However, we plan to conduct follow-up questionnaires and collect four outcomes: mortality, LTCI certification, onset of disableddementia, and long-term care costs. By analyzing this information and the baseline surveys, we can assess the influence of psychological and social factors on frailty and evaluate the impact of community-based interventions at the individual level. The results of this study may be applied not only to Kesennuma City but also to rural areas that were damaged by the tsunami in coastal rural areas, which have geographical features similar to Kesennuma City.

\section{ACKNOWLEDGEMENTS}

This study was supported by grants from Kesennuma City, a Grant-in-Aid for Research Activity start-up (Grants number: 19K24218) from the Japan Society for the Promotion of Science, and The Ito Foundation. We are very grateful to residents and staff members of Kesennuma City.

Conflicts of interest: None declared.

\section{APPENDIX A. SUPPLEMENTARY DATA}

Supplementary data related to this article can be found at https:// doi.org/10.2188/jea.JE20200599.

\section{REFERENCES}

1. National Police Agency. Damage situation and police countermeasures. https://www.npa.go.jp/news/other/earthquake2011/ pdf/higaijokyo.pdf; 2017 Accessed 2020.09.30.

2. Miyagi Prefectural Government. Occupancy status of emergency temporary housing. https://www.pref.miyagi.jp/uploaded/ attachment/795538.pdf; 2012 Accessed 2020.09.10.

3. Hikichi H, Sawada Y, Tsuboya T, et al. Residential relocation and change in social capital: a natural experiment from the 2011 Great East Japan Earthquake and Tsunami. Sci Adv. 2017;3(7):e1700426.

4. Hikichi H, Tsuboya T, Aida J, et al. Social capital prevents cognitive decline in the aftermath of a natural disaster: a quasi-experiment from the 2011 Great East Japan Earthquake and Tsunami. Lancet Planet Health. 2017;1(3):e105-e113.

5. Tomata Y, Suzuki Y, Kawado M, et al. Long-term impact of the 2011 Great East Japan Earth quake and tsunami on functional disability among older people: a 3-year longitudinal comparison of disability prevalence among Japanese municipalities. Soc Sci Med. 2015;147:296-299.

6. Li X, Buxton OM, Hikichi H, et al. Predictors of persistent sleep problems among older disaster survivors: a natural experiment from the 2011 Great East Japan Earthquake and Tsunami. Sleep. 2018; 41(7):zsy084.

7. Sone T, Nakaya N, Sugawara Y, et al. Longitudinal association between time-varying social isolation and psychological distress after the Great East Japan Earthquake. Soc Sci Med. 2016;152:96101.

8. Graham JE, Snih SA, Berges IM, et al. Frailty and 10-year mortality in community-living Mexican American older adults. Gerontology. 2009;55(6):644-651.

9. Kitamura A, Taniguchi Y, Seino S, et al. Combined effect of diabetes and frailty on mortality and incident disability in older Japanese adults. Geriatr Gerontol Int. 2019;19(5):423-428.

10. Shinkai S, Yoshida H, Taniguchi Y, et al. Public health approach to preventing frailty in the community and its effect on healthy aging in Japan. Geriatr Gerontol Int. 2016;16(Suppl 1):87-97.

11. Freiheit EA, Hogan DB, Eliasziw M, et al. Development of a frailty index for patients with coronary artery disease. J Am Geriatr Soc. 2010;58(8):1526-1531.

12. Mulasso A, Roppolo M, Giannotta F, et al. Associations of frailty and psychosocial factors with autonomy in daily activities: a crosssectional study in Italian community-dwelling older adults. Clin Interv Aging. 2016;11:37-45.

13. Meyer J. Qualitative research in health care. Using qualitative methods in health related action research. BMJ. 2000;320(7228):178-181.

14. Blair T, Minkler M. Participatory action research with older adults: key principles in practice. Gerontologist. 2009;49(5):651-662.

15. Geldsetzer P, Fawzi W. Quasi-experimental study designs seriespaper 2: complementary approaches to advancing global health knowledge. J Clin Epidemiol. 2017;89:12-16.

16. Haseda M, Takagi D, Kondo K, Kondo N. Effectiveness of community organizing interventions on social activities among older residents in Japan: a JAGES quasi-experimental study. Soc Sci Med. 2019;240:112527.

17. Nofuji Y, Seino S, Murayama H, et al. Process and outcome evaluation of community-based strategies for frailty prevention in the elderly with the help of the senior workforce at Silver Human Resources Centers in Yabu City, Japan. Nihon Koshu Eisei Zasshi. 2019;66(9):560-573 (in Japanese).

18. Shinkai S, Watanabe N, Yoshida H, et al. Research on screening for frailty: development of "the Kaigo-Yobo Checklist". Nihon Koshu Eisei Zasshi. 2010;57:345-354 (in Japanese).

19. Shinkai S, Watanabe N, Yoshida H, et al. Validity of the "Kaigo- 
Yobo Check-List" as a frailty index. Nihon Koshu Eisei Zasshi. 2013;60(5):262-274 (in Japanese).

20. Kojima G, Taniguchi Y, Kitamura A, Shinkai S. Are the Kihon Checklist and the Kaigo-Yobo Checklist compatible with the frailty index? J Am Med Dir Assoc. 2018;19:797-800.

21. Fried LP, Tangen CM, Walston J, et al. Frailty in older adults: evidence for a phenotype. J Gerontol A Biol Sci Med Sci. 2001;56: M146-M156.

22. Mitnitski AB, Mogilner AJ, Rockwood K. Accumulation of deficits as a proxy measure of aging. Sci World J. 2001;1:323-336.

23. Hoyl MT, Alessi CA, Harker JO, et al. Development and testing of a five-item version of the Geriatric Depression Scale. $J$ Am Geriatr Soc. 1999;47(7):873-878.

24. Rinaldi P, Mecocci P, Benedetti C, et al. Validation of the five-item geriatric depression scale in elderly subjects in three different settings. J Am Geriatr Soc. 2003;51(5):694-698.

25. Bertens AS, Moonen JEF, de Waal MWM, et al. Validity of the three apathy items of the Geriatric Depression Scale (GDS-3A) in measuring apathy in older persons. Int J Geriatr Psychiatry. 2017; 32(4):421-428.

26. Hughes ME, Waite LJ, Hawkley LC, Cacioppo JT. A short scale for measuring loneliness in large surveys: results from two populationbased studies. Res Aging. 2004;26(6):655-672.

27. Awata S, Bech P, Yoshida S, et al. Validation of the Japanese version of the World Health Organization-Five Well-Being Index in the context of detecting depression in diabetic patients. Psychiatry Clin Neurosci. 2007;61(1):112-119.

28. Fukutomi E, Okumiya K, Wada T, et al. Relationships between each category of 25-item frailty risk assessment (Kihon Checklist) and newly certified older adults under Long-Term Care Insurance: a 24-month follow-up study in a rural community in Japan. Geriatr Gerontol Int. 2015;15(7):864-871.

29. Oshio A, Abe S, Cutrone P, Gosling SD. Big Five content representation of the Japanese version of the Ten-Item Personality Inventory. Psychology. 2013;4(12):924-929.

30. Saito M, Kondo K, Ojima T, Hirai H; JAGES group. Criteria for social isolation based on associations with health indicators among older people. a 10-year follow-up of the Aichi Gerontological Evaluation Study. Nihon Koshu Eisei Zasshi. 2015;62(3):95-105 (in Japanese).
31. Saito J, Kondo N, Saito M, et al. Exploring 2.5-year trajectories of functional decline in older adults by applying a growth mixture model and frequency of outings as a predictor: a 2010-2013 JAGES longitudinal study. J Epidemiol. 2019;29(2):65-72.

32. Guralnik JM, LaCroix AZ, Abbott RD, et al. Maintaining mobility in late life. I. Demographic characteristics and chronic conditions. Am J Epidemiol. 1993;137(8):845-857.

33. Kim MJ, Seino S, Kim MK, et al. Validation of lower extremity performance tests for determining the mobility limitation levels in community-dwelling older women. Aging Clin Exp Res. 2009;21(6): 437-444.

34. Kimura M, Moriyasu A, Kumagai S, et al. Community-based intervention to improve dietary habits and promote physical activity among older adults: a cluster randomized trial. BMC Geriatr. 2013; 13:8.

35. Craig CL, Marshall AL, Sjöström M, et al. International physical activity questionnaire: 12-country reliability and validity. Med Sci Sports Exerc. 2003;35(8):1381-1395.

36. Kumagai $\mathrm{S}$, Watanabe $\mathrm{S}$, Shibata $\mathrm{H}$, et al. Effects of dietary variety on declines in high-level functional capacity in elderly people living in a community. Nihon Koshu Eisei Zasshi. 2003;50(12):1117-1124 (in Japanese).

37. Koyano W, Shibata H, Nakazato K, Haga H, Suyama Y. Measurement of competence: reliability and validity of the TMIG Index of Competence. Arch Gerontol Geriatr. 1991;13(2):103-116.

38. Tsutsui T, Muramatsu N. Care-needs certification in the long-term care insurance system of Japan. J Am Geriatr Soc. 2005;53:522527.

39. Seino S, Kitamura A, Tomine Y, et al. A community-wide intervention trial for preventing and reducing frailty among older adults living in metropolitan areas: design and baseline survey for a study integrating participatory action research with a cluster trial. J Epidemiol. 2019;29(2):73-81.

40. Murayama H, Nofuji Y, Matsuo E, et al. The Yabu cohort study: design and profile of participants at baseline. J Epidemiol. 2014; 24(6):519-525.

41. Henning-Smith C, Ecklund A, Kozhimannil K. Rural-urban differences in social isolation and its relationship to health. Innov Aging. 2018;2(Suppl 1):7. 